\title{
MEASURING THE EFFECT OF CARERS ON PATIENTS' RISK OF ADVERSE HEALTHCARE OUTCOMES USING THE CAREGIVER NETWORK SCORE
}

\author{
R. O’CAOIMH ${ }^{1,2,3}$, N. CORNALLY ${ }^{1,4}$, A. SVENDROVSKI ${ }^{5}$, E. WEATHERS ${ }^{1,4}$, C. FITZGERALD ${ }^{1}$,

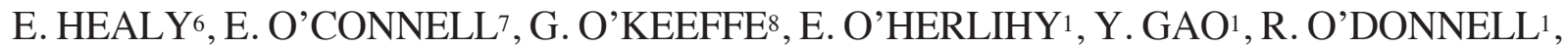 \\ R. O’SULLIVAN ${ }^{1}$, P. LEAHY-WARREN ${ }^{4}$, F. ORFILA ${ }^{9}$, C. PAÚL ${ }^{10}$, R. CLARNETTE ${ }^{11}$, D.W. MOLLOY ${ }^{1,3}$
}

\begin{abstract}
1. Centre for Gerontology and Rehabilitation, University College Cork, St Finbarr's Hospital, Douglas road, Cork City, Ireland; 2. Health Research Board Clinical Research Facility Galway, National University of Ireland, Galway, Geata an Eolais, University Road, Galway, Ireland; 3. COLLAGE (COLLaboration on AGEing), University College Cork, Cork City and Louth Age Friendly County Initiative, Co Louth, Ireland; 4. School of Nursing \& Midwifery, University College Cork, Ireland; 5. UZIK Consulting Inc., 86 Gerrard St E, Unit 12D, Toronto, ON, M5B 2J1 Canada; 6. Centre for Public Health Nursing, Ballincollig and Bishopstown, Co Cork, Ireland; 7. Centre for Public Health Nursing, Mahon and Ballintemple, Cork City, Ireland; 8. Health Service Executive, South, Ireland; 9. Institute for Research Primary Healthcare, Jordi Gol University, Barcelona, Spain; 10. ICBAS, Institute of Biomedical Sciences Abel Salazar - University Of Porto, Porto, Portugal; 11. School of Medicine and Pharmacology, University of Western Australia, 35 Stirling Hwy, Crawley WA 6009, Australia. Corresponding author: Dr Rónán O’Caoimh, Email: rocaoimh@ hotmail.com, Telephone: +353214901461, Facsimile: +3534901635
\end{abstract}

\begin{abstract}
Background: Although caregivers are important in the management of frail, community-dwelling older adults, the influence of different caregiver network types on the risk of adverse healthcare outcomes is unknown. Objective: To examine the association between caregiver type and the caregiver network subtest of The Risk Instrument for Screening in the Community (RISC), a five point Likert scale scored from one ("can manage") to five ("absent/liability"). To measure the association between caregiver network scores and the one-year incidence of institutionalisation, hospitalisation and death. Design: Observational cohort study. Setting and Participants: Community-dwelling adults, aged $>65$,attending health centres in Ireland, $(\mathrm{n}=779)$. Procedure and Measurements: The caregiver network subtest of the RISC was scored by public health nurses. Caregivers were grouped dichotomously into low-risk (score of one) or high-risk (scores two-five). Results: The majority of patients had a primary caregiver (582/779;75\%), most often their child (200/582;34\%). Caregiver network scores were highest, indicating greatest risk, when patients had no recognised primary caregiver and lowest when only a spouse or child was available. Despite this, patients with a caregiver were significantly more likely to be institutionalised than those where none was required or identified $(11.5 \%$ versus $6.5 \%, \mathrm{p}=0.047)$. The highest one-year incidence of adverse outcomes occurred when state provided care was the sole support; the lowest when private care was the sole support. Significantly more patients whose caregiver networks were scored high-risk required institutionalisation than low-risk networks; this association was strongest for perceived difficulty managing medical domain issues, odds ratio (OR) 3.87:(2.22-6.76). Only perceived difficulty managing ADL was significantly associated with death, OR 1.72:(1.06-2.79). There was no association between caregiver network scores and risk of hospitalisation. Conclusion: This study operationalizes a simple method to evaluate caregiver networks. Networks consisting of close family (spouse/children) and those reflecting greater socioeconomic privilege (private supports) were associated with lower incidence of adverse outcomes. Caregiver network scores better predicted institutionalisation than hospitalisation or death.
\end{abstract}

Key words: Caregivers, social networks, frailty, risk assessment, community assessment.

\section{Introduction}

Population ageing in the European Union is associated with an increased prevalence of frailty in community-dwelling older adults (1). This ageing phenomenon is fraught with socioeconomic difficulties and it remains unclear how best to address these challenges (2). One strategy, proposed by the European Innovation Partnership on Active and Healthy Ageing (EIP on AHA), is to maintain older adults in their own homes for longer by preventing or delaying the onset of frailty, through targeted interventions when independent living appears compromised (3-7). Early identification of those most likely to experience decline and the prompt initiation of corrective measures to avoid the development of adverse healthcare outcomes, together with understanding and supporting patients' home support networks is a key part of this strategy (8).

Caregiver networks are a central component in the management of frail and functionally impaired communitydwelling older adults (9). They are associated with the mental state (10), activities of daily living (ADL) (11) and medical state (12) of patients, as well as their self-reported health status (13). They vary in nature between developed (14) and developing countries (9). Inadequate caregiver networks and those experiencing caregiver strain or burnout, are associated with an increased risk of adverse healthcare outcomes including institutionalisation (15-17), hospitalisation (18) and death (19).

The composition of caregiver networks can include informal (family and friends) (20) and formal (healthcare professionals and services) supports. Their ability to manage patients can span across a spectrum from an ability to fully manage a 


\section{THE JOURNAL OF FRAILTY \& AGING}

patients' care needs (17) to those that are fragmented, a liability (18) or absent, putting patients at increased risk (21). Efficient and functioning networks provide economic (12) and quality of life (13) related benefits.

The Risk Instrument for Screening in the Community (RISC) is a short (22), reliable $(23,24)$, and valid, (25-30) global risk-prediction screen, designed for use by community healthcare workers and was developed as part of Irelands' EIP on AHA three-star reference site, the COLLaboration on AGEing (COLLAGE) (see the Community Assessment of Risk and Treatment Strategies (CARTS) study at www.collageireland.eu) $(31,32)$. The RISC identifies the presence and severity of concern across three domains (mental state, ADL and medical state), and scores the ability of an individuals' caregiver network to manage the patients' care needs. It quantifies the one-year risk of three adverse outcomes: hospitalisation, institutionalisation and death.

To date, the association between caregiver networks and the risk of developing adverse healthcare outcomes remains poorly understood. We investigated the extent to which an individuals' caregiver or social network, measured using the caregiver network subtest of the RISC, is associated with the three domains of the RISC and one-year incidence of three adverse healthcare outcomes: institutionalisation, hospitalisation, and death.

\section{Materials and Methods}

\section{The Risk Instrument for Screening in the Community (RISC)}

The RISC collects demographic data and scores three domains: mental state, ADL (functional state) and medical state using three components, called "steps". The first step is scored dichotomously (Yes/No) to identify if there is a concern in each domain. If no problem is identified the rater moves on to the next domain. If there is, the severity of the concern (second step) is scored on a scale from one to three (mild, moderate or severe). The third step, scores the ability of the caregiver network to manage each domain, using a five-point Likert scale from 1-5 (1=Caregiver network is required but "can manage"; 2="carer strain"; 3="some gaps"; 4="cannot manage"; $5=$ "absent/liability"). The severity of the concern and the ability of the caregiver network are taken into account when completing the three subjective global risk scores of institutionalisation, hospitalisation and death. The RISC score sheet is available at: http://www.biomedcentral.com/14712318/14/104/figure/F1.

\section{Scoring of the Caregiver Network}

Healthcare professionals scoring the caregiver network subtest of the RISC are required to take all the formal and informal resources available to the person into account. It is scored from one (low-risk) to five (high-risk). If there is no concern in any domain, the caregiver network is not scored (n/a). "Can manage" $(1 / 5)$ is scored when concerns in that domain are well managed by the caregiver network. "Carer strain" $(2 / 5)$ is scored where there are perceived imbalances between care demands and the resources available, but patients care needs are still being managed $(33,34)$. "Some gaps" $(3 / 5)$ is scored if the network is perceived to be managing most of the concerns, but there are gaps in the provision of care e.g. there are periods when the patient is left alone when supervision is required. "Cannot manage" (4/5) is scored where patients require care but refuse or where the caregiver network is failing e.g. due to excessive work-load caring for a deteriorating patient or where caregiver burnout is present. "Absent/liability" $(5 / 5)$ is scored only where the network is unable to provide the care required e.g. no support available or the caregiver(s) is frail or has significant medical problems him/herself (nonfunctional), or the patient provides care for the supposed caregiver, or if there is concern over actual or potential elder abuse (physical, emotional, sexual, financial or other) or where family or other next of kin are refusing care that is required by the patient. To analyze the data, patients caregiver network scores were subsequently divided into those perceived as lowrisk, a score of $1 / 5$ ("can manage"), and high-risk, scores 2-5/5 ("carer strain/not managing").

\section{Patients}

The CARTS study is an observational prospective cohort study of 803 patients. Patients are community-dwelling older adults aged over 65 years, recently reviewed and under longterm follow-up by their public health nurse (PHN). In Ireland, PHNs provide the core nursing services in the community, and manage large numbers of frail older adults (35). The baseline characteristics of these patients have been published previously (22). In summary, the median age of patients was 80 years (interquartile range $+/-10$ ) and $64 \%$ were female. Additional demographics and the results of a selection of cognitive and functional assessments were also available. The median Barthel Index (BI) score was $18(+/-6)$, Abbreviated Mental Test Score (AMTS) was ten $(+/-<1)$, Charlson Co-morbidity Index score one (+/- two), and the Clinical Frailty Score (CFS) (36) was five ( $+/$ - two).

Caregiver networks were divided into nine subtypes: (I) none, (II) spouse, (III) child, (IV) extended family unit, (V) siblings or other distant family, (VI) private support (privately funded home care etc.), (VII) friends or neighbours, (VIII) state support and (IX) others. 'None' refers to patients without an identifiable caregiver network, irrespective of need. Extended family units included patients who live with several family members, including different generations of the same family such as children and grandchildren. 'Sibling or other distant family', included other relatives such as cousins, nieces and nephews. 'Private support' was self-funded home-help, (formal assistance with instrumental and or personal ADLs provided for limited periods by trained carers according to private funding resources). 'State provided support' included government 


\section{EFFECTS OF CAREGIVERS ON RISK ASSESSMENT}

funded home-help or temporary respite care in a nursing home. 'Others' covered patients in a convent, religious order or in sheltered accommodation. Where more than one caregiver type was identified, the main provider was judged by each patients' PHN.

\section{Data collection and Sampling}

The CARTS study (22) included patients from PHN sectors in County Cork, Ireland. PHNs from two community care areas were the first respondents and were sampled based on the non-probability method of convenience sampling, using a quota method. All PHNs $(n=15)$ from these centres were trained and certified in scoring the RISC (23). Scoring was based on the PHNs knowledge of patients and PHNs only scored those directly under active follow-up. Demographic data were recorded from PHN records by a clinician, blinded to the RISC scores. Where possible, the primary caregiver was identified. One year follow-up data on hospitalisation and death were obtained from the Hospital In-Patient Enquiry system of all acute hospitals. Followup data on institutionalisation were obtained from the Cork Local Placement Forum. Institutionalisation was defined as admission to low dependency (general nursing homes) and high dependency (community hospital) long-term care facilities. Sheltered accommodation (assisted living /supportive housing programmes), continuing care, retirement communities, or home care were not counted. Hospitalisation included, acute admissions to acute (secondary or tertiary referral) hospitals. Elective admissions or planned rehabilitation were not included.

The Clinical Research Ethics Committee of the Cork Teaching Hospitals granted ethical approval for the CARTS study. Although consent was not required for retrospective chart review, informed written consent was obtained for all patients included in the CARTS intervention study.

\section{Statistical analysis}

Data were analysed using SPSS version 20.0. The KruskalWallis test compared distributions of caregiver network scores. Chi-square tests were performed to explore associations between the caregiver network scores and other variables, with Cramer's V $(\phi c)$ used as a measure of the strength of association (higher values $=$ greater strength). The MantelHaenszel method was used to estimate the odds ratio (OR), measuring the association between each variable and outcome.

\section{Results}

\section{Baseline caregiver characteristics and outcomes}

Caregiver network scores were available for 779/803 (97\%) patients. The social circumstances of the remaining 24 were unclear and they were excluded from this analysis. A potential primary caregiver was identified for 582/779 (74.7\%) patients, with $197 / 779(25.3 \%)$ regarded as sufficiently independent to not have or require a carer. Children $(200 / 779,26 \%)$ were the most common primary caregiver followed by extended family $(148 / 779,19 \%)$, a spouse $(134 / 779,17 \%)$ and sibling or other distant family members, e.g. nephews, nieces and cousins $(57 / 779,7 \%)$. In a small proportion of cases, the primary caregiver was identified as others $(5.5 \%)$ : private support $(<1 \%)$, state provided support $(2.2 \%)$, neighbours or friends $(1 \%)$ and miscellaneous $(1.7 \%)$. The majority of patients $(412 / 779,53 \%)$ were living with someone. Of these, 260/412 $(63 \%)$ were living only with a spouse, $70(17 \%)$ only with a child, $46(11 \%)$ within an large extended family unit and 36 (9\%) with 'others'.

Characteristics of patients' caregiver networks are presented in Table 1. There were no differences in age, gender or percentage living alone between those with and without a recognised carer. Those without a primary caregiver were less likely to be cognitively impaired $(\mathrm{p}<0.001)$, frail $(\mathrm{p}<0.001)$ and more likely to be functionally independent according to the BI $(p<0.001)$ than patients with an identified primary caregiver. The highest prevalence of cognitive impairment was found among patients whose caregiver network was recorded as their spouse $(43 \%)$ or extended family units $(42 \%)$. Few patients without a primary caregiver (12\%) had cognitive impairment. Median BI scores were highest for those without a primary caregiver (20 2 ), suggesting independence, and lowest for those receiving state support e.g. home help $(15 \pm 8)$ or where an extended family unit was identified as the primary caregiver $(16 \pm 7)$. Levels of frailty, measured using the CFS or PHNs global assessments (frail yes or no), were highest for patients where spouses $(6 \pm 2)$ were the main carers and lowest for those where siblings or other distant family $(3 \pm 2)$ or no caregiver network ('none') $(4 \pm 2)$ were identified as the primary care providers. A large percentage of all patients, irrespective of caregiver network type, were receiving some home help (range from $38-65 \%$ ), provided by the state.

At one-year, the incidence of the three outcomes was $10.2 \%$ for institutionalisation, $17.7 \%$ for hospitalisation (at least one) and $15.6 \%$ for death. Patients with an established caregiver experienced more of all three outcomes than those where no primary caregiver was required or could be identified ('none'), although this was only of statistical significance for institutionalisation, $11.5 \%$ versus $6.5 \%, \mathrm{p}=0.047$ (see Table 1). Patients with a sibling or other distant family (17.2\%) and those where 'others' were the primary caregivers (13.8\%), had the highest incidence of institutionalisation. The lowest rate of institutionalisation occurred when the spouse was the recognised primary carer $(5.2 \%)$. Those where an extended family unit was identified as the primary support had the highest death rates (19.3\%). Although the absolute numbers were small, half of patients (50\%) with a friend or neighbour acting as the primary carer were hospitalised. Where state support alone was recognized as the primary caregiver network, patients had the highest overall incidence of institutionalisation $(23.5 \%)$ and death $(23.5 \%)$. Patients whose friends or 
THE JOURNAL OF FRAILTY \& AGING

Table 1

Characteristics of caregiver network types where available $(n=779)$

\begin{tabular}{|c|c|c|c|c|c|c|c|c|}
\hline Variable & None & $\begin{array}{l}\text { Primary caregi- } \\
\text { ver identified }\end{array}$ & $\mathbf{p}=\mathbf{X}$ & Spouse & Child & $\begin{array}{c}\text { Extended family } \\
\text { unit }\end{array}$ & $\begin{array}{l}\text { Sibling or other } \\
\text { distant family }\end{array}$ & Others* \\
\hline Number $(\mathrm{n}=779)(\%)$ & $197(25.3 \%)$ & $582(74.7 \%)$ & - & $134(17.2 \%)$ & $200(25.7 \%)$ & $148(19.0 \%)$ & $57(7.3 \%)$ & $43(5.5 \%)$ \\
\hline Age (Median \pm IQR) & $79 \pm 10(74-84)$ & $81 \pm 10(75-85)$ & 0.06 & $77.5 \pm 9(73-82)$ & $84 \pm 10(78-88)$ & $80 \pm 11(75-86)$ & $80 \pm 10(75-85)$ & $78 \pm 11(72-83)$ \\
\hline Female $(\%)$ & $63 \%$ & $65 \%$ & 0.57 & $46 \%$ & $77 \%$ & $69 \%$ & $69 \%$ & $53 \%$ \\
\hline Living alone (\%) & $48 \%$ & $47 \%$ & 0.80 & $2 \%$ & $61 \%$ & $47 \%$ & $79 \%$ & $82 \%$ \\
\hline Cognitive Impairment & $12 \%$ & $37 \%$ & $<0.001$ & $43 \%$ & $32 \%$ & $42 \%$ & $20 \%$ & $41 \%$ \\
\hline $\begin{array}{l}\text { AMTS score (Median } \\
\pm \text { IQR) }\end{array}$ & $10 \pm 0(10-10)$ & $\begin{array}{l}10 \pm 0(10-10) \\
\text { Mean }=9.09\end{array}$ & $<0.001$ & $10 \pm 1(9-10)$ & $10 \pm 0(10-10)$ & $10 \pm 1(9-10)$ & $10 \pm 0(10-10)$ & $10 \pm 0(10-10)$ \\
\hline $\begin{array}{l}\text { Barthel Index score } \\
\text { (Median } \pm \mathrm{IQR})\end{array}$ & $20 \pm 2(18-20)$ & $17 \pm 6(13-19)$ & $<0.001$ & $17 \pm 6(13-19)$ & $17 \pm 6(13-19)$ & $16 \pm 7(12-19)$ & $18 \pm 5(15-20)$ & $18 \pm 5(15-20)$ \\
\hline $\begin{array}{l}\text { Medications (Median } \\
\pm \text { IQR) }\end{array}$ & $4 \pm 5(2-7)$ & $5 \pm 5(3-8)$ & 0.004 & $6 \pm 4(4-8)$ & $5 \pm 5(3-8)$ & $6 \pm 6(3-9)$ & $5 \pm 3(3-6)$ & $5 \pm 4(4-8)$ \\
\hline Receiving home help (\%) & $38 \%$ & $57 \%$ & $<0.001$ & $47 \%$ & $65 \%$ & $55 \%$ & $52 \%$ & $60 \%$ \\
\hline $\begin{array}{l}\text { Hospital length of stay } \\
\text { (Median } \pm \mathrm{IQR})\end{array}$ & $0 \pm 0(0-0)$ & $0 \pm 0(0-0)$ & 0.76 & $0 \pm 0(0-0)$ & $0 \pm 0(0-0)$ & $0 \pm 0(0-0)$ & $0 \pm 0(0-0)$ & $0 \pm 0(0-0)$ \\
\hline $\begin{array}{l}\text { Clinical Frailty Scale } \\
\text { (Median } \pm \text { IQR) }\end{array}$ & $4 \pm 1(3-4)$ & $5 \pm 2(4-6)$ & $<0.001$ & $6 \pm 2(4-6)$ & $5 \pm 2(4-6)$ & $5 \pm 2(4-6)$ & $4 \pm 3(3-6)$ & $5 \pm 3(3-6)$ \\
\hline $\begin{array}{l}\text { PHN frailty perception } \\
(\mathrm{n}=335 ; 42 \%)\end{array}$ & $19 \%$ & $49 \%$ & $<0.001$ & $57 \%$ & $53 \%$ & $47 \%$ & $37 \%$ & $35 \%$ \\
\hline $\begin{array}{l}\text { Charlson Comorbidity } \\
\text { Index (Median } \pm \text { IQR) }\end{array}$ & $1 \pm 2(0-2)$ & $\begin{array}{c}1 \pm 2(0-2) \\
\text { Mean }=1.42\end{array}$ & 0.001 & $1 \pm 2(1-3)$ & $1 \pm 2(0-2)$ & $1 \pm 2(0-2)$ & $1 \pm 2(0-2)$ & $1 \pm 1(0-1)$ \\
\hline $\begin{array}{l}\text { Institutionalisation } \\
(\mathrm{n}=82 ; 10.2 \%)\end{array}$ & $\mathrm{n}=13(6.5 \%)$ & $\mathrm{n}=69(11.5 \%)$ & 0.047 & $\mathrm{n}=7(5.2 \%)$ & $\mathrm{n}=25(12.4 \%)$ & $\mathrm{n}=19(12.7 \%)$ & $\mathrm{n}=10(17.2 \%)$ & $\mathrm{n}=8(13.8 \%)$ \\
\hline $\begin{array}{l}\text { Hospitalisation } \\
(\mathrm{n}=142 ; 17.7 \%)\end{array}$ & $\mathrm{n}=35(17.6 \%)$ & $\mathrm{n}=107(17.8 \%)$ & 0.95 & $\mathrm{n}=30(22.2 \%)$ & $\mathrm{n}=32(15.9 \%)$ & $\mathrm{n}=22(14.7 \%)$ & $\mathrm{n}=12(20.7 \%)$ & $\mathrm{n}=11(19.0 \%)$ \\
\hline $\begin{array}{l}\text { Death } \\
(\mathrm{n}=125 ; 15.6 \%)\end{array}$ & $\mathrm{n}=24(12.1 \%)$ & $\mathrm{n}=101(16.8 \%)$ & 0.11 & $\mathrm{n}=22(16.3 \%)$ & $\mathrm{n}=36(17.9 \%)$ & $\mathrm{n}=29(19.3 \%)$ & $\mathrm{n}=7(12.1 \%)$ & $\mathrm{n}=7(12.1 \%)$ \\
\hline
\end{tabular}

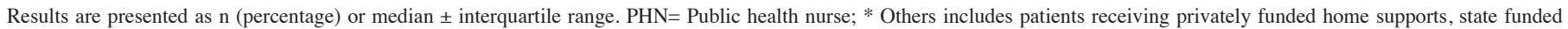
home supports, care from friends and neighbours etc

neighbours were the primary caregiver network had the highest incidence of hospitalisation (50\%) while those receiving private support (home-help) had the lowest (0\%).

\section{Caregiver Network Scores}

A significantly higher proportion of patients were scored $\geq 1$ (some concern) for the medical state (87\%), and ADL (76\%) domains than for the mental state (39\%) domain of the RISC, $\mathrm{p}<0.001$. The ability of caregiver networks to manage each of the three domains, at baseline, is presented in Table 2. The OR for each adverse outcome, comparing caregiver networks scored as low-risk ("can manage", score of 1/5) or high-risk ("carer strain/not managing", scores 2-5/5) are presented in Table 3. A greater percentage of networks were scored as high-risk (2-5/5) for medical state domains (33\% of networks) compared with ADL (20\%) and mental state (12\%) domains. Irrespective of the domain, most caregiver networks were perceived to be low-risk at baseline. A significantly greater proportion of patients with caregiver networks scored as highrisk for mental state domains were institutionalised, within one year of assessment, than those assessed as low-risk (23\% versus $12 \%$ respectively, $\mathrm{p}=0.021$ ). There was a significantly greater incidence of institutionalisation in high-risk networks for ADL $(26 \%$ versus 9\%, $\mathrm{p}<0.001)$ and medical state domains $(27 \%$ versus $9 \%, \mathrm{p}<0.001)$. When caregiver networks were perceived to be high-risk, the odds of institutionalisation within the next year were significantly increased for all three domains; the OR was highest where the network scored highrisk for medical state domains, OR 3.87 (95\% CI:2.22-6.76). Caregiver networks scored as high-risk also had greater odds of institutionalisation than low-risk, for the mental state (2.07) and ADL (3.48) domains. There was a small difference, of borderline significance, in the one-year incidence of hospitalisation ( $26 \%$ versus $18 \%, \mathrm{p}=0.05)$ and death $(24 \%$ versus $16 \%, \mathrm{p}=0.03$ ) between caregiver networks scored as high and low-risk for the ADL domain. ADL was the only domain significantly associated with the one-year incidence of death, OR 1.72 (95\% CI:1 .06-2.79). No significant associations were found for risk of hospitalisation. 


\section{EFFECTS OF CAREGIVERS ON RISK ASSESSMENT}

Table 2

Characteristics of patients including Risk Instrument for Screening in the Community (RISC) scores (low-risk=score of 1, highrisk $=2-5 / 5$ ) according to adverse healthcare outcome: institutionalisation, hospitalisation and death

\begin{tabular}{|c|c|c|c|c|c|}
\hline Variable & Categories & Total & Institutionalised & Hospitalised & Dead \\
\hline \multicolumn{6}{|c|}{ Mental state caregiver network concern score $n=305 / 779(39 \%)$} \\
\hline & Low-risk & $203 / 305(67 \%)$ & $25 / 203(12 \%)$ & $36 / 203(18 \%)$ & $41 / 203(20 \%)$ \\
\hline \multicolumn{6}{|c|}{ ADLs caregiver network concern score $n=593 / 779(76 \%)$} \\
\hline & Low-risk & $473 / 593(80 \%)$ & $43 / 473(9 \%)$ & $85 / 473(18 \%)$ & $74 / 473(16 \%)$ \\
\hline \multicolumn{6}{|c|}{ Medical state caregiver network concern score $n=680 / 779(87 \%)$} \\
\hline & Low-risk & $595 / 680(88 \%)$ & $52 / 595(9 \%)$ & $106 / 595(18 \%)$ & $92 / 595(15 \%)$ \\
\hline & High-risk & $85 / 680(12 \%)$ & $23 / 85(27 \%) \dagger$ & $20 / 85(24 \%)$ & $20 / 85(24 \%)$ \\
\hline
\end{tabular}

Comparison between high and low-risk groups $* \mathrm{p}<0.05 ; \uparrow \mathrm{p}<0.001$

Table 3

Comparing odds ratios (95\% Confidence intervals) between caregiver networks classified either as low-risk "can manage" (score 1/5) or high-risk "under strain/not managing" (scores 2-5/5), for the three domains of the RISC and each adverse outcome

\begin{tabular}{llll}
\hline Domain & Institutionalisation & Hospitalisation & Death \\
\hline Mental state & $2.07(1.11-3.87)^{*}$ & $1.35(0.75-2.43)$ & $0.85(0.46-1.56)$ \\
ADL & $3.48(2.08-5.83)^{*}$ & $1.59(0.99-2.55)$ & $1.72(1.06-2.79)^{*}$ \\
Medical state & $3.87(2.22-6.76)^{*}$ & $1.42(0.82-2.44)$ & $1.68(0.97-2.91)$ \\
\hline
\end{tabular}

$* \mathrm{p}<0.05 ;$ Low-risk group $=$ reference group

\section{Conclusion}

This study reports the characteristics and prevalence of caregiver network types in a sample of community-dwelling older adults under active follow-up by their PHN. It examines the association between caregiver networks, the three domains of the RISC and the one-year incidence rate of three adverse healthcare outcomes: institutionalisation, hospitalisation and death. Of those included, most had close family (spouse, child or an extended family unit) identified as their primary carer. In this sample those without a recognised caregiver network ('none') had low levels of frailty, cognitive and functional impairment and generally had a low incidence of adverse outcomes. Although numbers were small and confounding factors may have influenced results, patients with only stateprovided support as their primary caregiver (e.g. home-help or respite) had the highest incidence of adverse outcomes. Those with privately funded supports had the lowest incidence. Excluding these groups, with small numbers, showed that no single caregiver type had the highest incidence of adverse outcomes in each group, see Table 1. Most caregiver networks were scored as low on the RISC suggesting that these "can manage' each of the three domains measured: mental state, ADL or medical state. High-risk scores were significantly associated with an increased incidence of institutionalisation in all three RISC domains particularly for the medical state, which had the highest OR for admission to long-term care. This association is expected as struggling support networks are recognised to increase patients' risk of nursing home admission $(16,17)$, particularly for those with multiple co-morbidities, where the presence of an informal caregiver does not guard against institutionalisation (37). The ability of caregivers to manage appeared to have little effect on risk of hospitalisation. There was only a small increase (26\% versus $18 \%$ ), of borderline significance, in hospital admissions where caregiver networks were high-risk for managing ADL. Again, this would be expected, as risk of hospital admission is particularly difficult to predict (38). Risk of death was only significantly associated with difficulty managing ADLs, likely reflecting the association between medical co-morbidities such as Stroke (39) and Parkinson's (40), functional impairment and mortality.

Even though patients without a recognised primary caregiver generally have low levels of cognitive impairment, frailty and ADL disability, and are more likely to be independent than those living with a carer (37), PHNs in this study considered that the lack of an informal caregiver was 'risky'. PHNs scored the caregiver network highest for the ADL and mental state domains when no primary caregiver was identified. This is complicated by the fact that $38 \%$ of patients without a defined caregiver were receiving some state support (home 


\section{THE JOURNAL OF FRAILTY \& AGING}

help hours), although these were not considered sufficient by the PHN (less than five hours/week) to count as a primary caregiver. Thus, PHNs often scored caregiver networks without a primary caregiver as high-risk even where some assistance was provided by the state. This suggests that a lack of informal supports was perceived as a greater risk than lack of formal supports. In other studies the lack of a suitable caregiver network was associated with a moderate increase in institutionalisation (OR 1.8) (41), hospitalisation (OR 2.59) (42) and mortality (OR 1.5) (43). In this study those without a recognised caregiver network were less likely to be institutionalised but there was no significant difference in the incidence of hospitalisation or death. Although more patients with a primary caregiver were admitted to a nursing home, this was predominantly due to high levels of independence in those without a carer and high institutionalisation rates in those patients with specific carer profiles: patients with a sibling or other distant family and those with state support alone as primary caregiver.

The caregiver-patient dyad is complex and previous studies have suggested that informal care, usually provided by family and friends, only substitutes for formal homecare when ADL disability is low (20). This likely explains why patients included in this study, under PHN follow-up and with higher levels of frailty and comorbidity than the general population, were usually in receipt of both formal and informal care. Similarly, living alone, as a binary evaluation, is a poor predictor of adverse healthcare outcomes as it misses the complexity of social relationships and their ability to protect against adverse events (43). The high levels of concern over caregiver networks' ability to manage patients' mental state, where the primary caregiver was a sibling or other distant family member, suggests that these type of networks may be less able to manage mental state domain issues like the behavioral and psychological symptoms of dementia (44). Likewise, spouses experience carer strain differently to siblings. For siblings the quality of the prior relationship with the recipient may be more important (45). Extended family units, arguably more complete and resilient networks, were associated with the lowest caregiver network scores in most domains.

The strengths of this study include the large and representative sample of patients under active PHN follow-up. Another strength is that social relationships were measured individually. This is important as patients who live alone may have a large supportive social network (43). This paper represents data from an ongoing prospective study and future analysis will allow the significance of these relationships to be measured over time (46). This paper has limitations. Caregiver networks could not be identified for some patients (3\%) due to some incomplete records. The numbers of patients with some networks, such as those only receiving private or state supported home supports, were small and it was not possible to draw meaningful conclusions from this data. Future, larger studies, should examine the influence of these networks on risk of adverse healthcare outcomes. In addition, it was not possible to distinguish with certainty those without a caregiver network and that didn't require one from those who needed support but did not currently receive any. That said, sensitivity analysis subsequently removed patients whose caregiver networks were deemed able to manage (caregiver network scores $<2 / 5$ ) and this did not significantly affect the results. Further, no formal measure of caregiver strain was recorded to compare to the caregiver network component of the RISC. However, the intention here was not to measure caregiver burden but instead to identify the ability of the caregiver networks to manage using a simple, short, subjective, global risk assessment. Finally, the method of sampling and the study population, i.e. those under active follow-up by their PHN, may have led to selection bias towards patients with high levels of frailty, at higher risk of adverse outcomes than a cross sectional sample of all older community dwellers.

In summary, this paper discusses the association between caregiver networks and risk of adverse healthcare outcomes. It operationalises a simple method for community healthcare providers to evaluate caregiver networks using a Likert scale from one to five. PHNs had most concern over caregivers' ability to manage ADLs. There were differences found between spouses and children, who are likely to provide hands-on care and remote carers such as siblings or other distant family, friends and neighbours who are less likely to provide hands-on care. Concern was lowest when close family members were seen as the primary caregiver, particularly in the management of ADL. Patients without caregiver networks had low levels of ADL disability, cognitive impairment and a relatively low incidence of adverse outcomes, particularly institutionalisation, likely reflecting their higher functional scores. Despite this PHNs often considered these networks to be high-risk, suggesting that a lack of social supports, even in those who remain independent, is seen as posing a risk. Irrespective of the type of network available, caregiver networks scored as high-risk, "carer strain/not managing", on the RISC caregiver network score were at a significantly greater likelihood of institutionalisation at one-year, compared to those scored as low-risk, "can manage". There was no significant difference for risk of hospitalisation, irrespective of domain. Thus, describing caregiver networks in simple terms of those that can (low-risk) and cannot (high-risk) manage may serve a useful purpose. Further study is required to examine the interplay between caregiver networks, adverse healthcare outcomes and caregiver strain to investigate if targeting and modifying these can reduce risk for community-dwelling older adults.

Acknowledgements: This research was conducted with the support of the Health Service Executive of Ireland (South) and the public health nurses in the Centres for Public Health Nursing in Ballincollig \& Bishopstown and Mahon \& Ballintemple.

Conflicts of interest: none. 


\section{EFFECTS OF CAREGIVERS ON RISK ASSESSMENT}

\section{References}

1. Santos-Eggimann B, Cuenoud P, Spagnoli J, Junod J. Prevalence of Frailty in Middle-Aged and Older Community-Dwelling Europeans Living in 10 Countries. J Gerontol A Biol Sci Med Sci 2009;64:675-681.

2. Global elderly care in crisis. Lancet 2014;383 (9921):927.

3. Bousquet J, Michel JP, Strandberg T, Crooks G, Iakovidis I, Iglesia M. The European Innovation Partnership on Active and Healthy Ageing: The European geriatric medicine introduces the EIP on AHA column. Eur Geriatr Med 2014;5:361-362.

4. Courtney M, Edwards H, Chang A, Parker A, Finlayson K, Hamilton K. Fewer emergency readmissions and better quality of life for older adults at risk of hospital readmission: a randomized controlled trial to determine the effectiveness of a 24-week exercise and telephone follow-up program. J Am Geriatr Soc $2009 ; 57: 395-402$.

5. Grimmer K, Luker J, Beaton K, Kumar S, Crockett A, Price K. TRialing individualized interventions to prevent functional decline in at-risk older adults (TRIIFL): study protocol for a randomized controlled trial nested in a longitudinal observational study. Trials 2013;14:266.

6. Caplan GA, Williams AJ, Daly B, Abraham K. A Randomized, Controlled Trial of Comprehensive Geriatric Assessment and Multidisciplinary Intervention After Discharge of Elderly from the Emergency DepartmentThe DEED II Study. J Am Geriatr Soc 2004;52:1417-1423.

7. Christensen C, Dobhlhammer G, Rau R, Vaupel J. Ageing populations: the challenges ahead. Lancet 2009;374:1196-208.

8. Lopez-Hartmann M, Wens J, Verhoeven V, Remmen R. The effect of caregiver support interventions for informal caregivers of communitydwelling frail elderly: a systematic review. Int J Integr Care 2012;12:e133.

9. Vladislavovna Doubova (Dubova) S, Pérez-Cuevas R, Espinosa-Alarcón P, Flores-Hernández S. Social network types and functional dependency in older adults in Mexico. BMC Public Health 2010; 10: 104.

10. Fiori KL, Antonucci TC, Cortina KS. Social network typologies and mental health among older adults. J Gerontol B Psychol Sci Soc Sci 2006;61:P2532.

11. Feld S, Dunkle RE, Schroepfer T, Shen HW. Expansion of elderly couples' IADL caregiver networks beyond the marital dyad. Int J Aging Hum Dev 2006;63:95-113.

12. Reeves D, Blickem C, Vassilev I, et al. The contribution of social networks to the health and self-management of patients with long-term conditions: a longitudinal study. PLoS One 2014;9:e98340.

13. Kawachi I, Kennedy BP, Glass R. Social capital and self-rated health: A contextual analysis. Am J Public Health 1999;89:1187-1193.

14. Fiori KL, Smith J, Antonucci TC. Social network types among older adults: a multidimensional approach. J Gerontol B Psychol Sci Soc Sci 2007;62:P322-30.

15. Jette $A M$, Tennestedt $S$, Crawford $S$. How does formal and informal community care affect nursing home use? J Gerontol B Psychol Sci Soc Sci 1995;50B:S4-S12.

16. Wachtel TJ, Derby C, Fulton JP. Predicting the Outcome of Hospitalization for Elderly Persons: Home Versus Nursing Home. South Med J 1984;77:1283-1285.

17. McCann M, Donnelly M, O'Reilly D. Living arrangements, relationship to people in the household and admission to care homes for older people. Age Ageing 2011;40:358-363.

18. Dong X, Simon MA. Elder Abuse as a Risk Factor for Hospitalization in Older Persons. JAMA Intern Med 2013;173:911-917.

19. Litwin H, Shiovitz-Ezra S. Network type and mortality risk in later life. Gerontologist 2006; 46:735-43.

20. Bonsang E. Does informal care from children to their elderly parents substitute for formal care in Europe? J Health Econ 2009;28:143-54.

21. Fulmer T, Paveza G, VandeWeerd C, et al. Dyadic vulnerability and risk profiling for elder neglect. Gerontologist 2005;45:525-34.

22. O’Caoimh R, Gao Y, Svendrovski A, et al. Screening for markers of frailty and perceived risk of adverse outcomes using the Risk Instrument for Screening in the Community (RISC). BMC Geriatrics 2014;14:104.

23. O'Caoimh R, Healy E, O Connell E, Gao Y, Molloy DW. The Community Assessment of Risk Tool, (CART): Investigation of Inter-Rater Reliability for a New Instrument measuring risk of Adverse Outcomes in Community Dwelling Older Adults. Irish J Med Sci 2012;181 S(7):227.
24. Clarnette RM, Ryan JP, O' Herlihy E, et al. The Community Assessment of Risk Instrument: Investigation of Inter-Rater Reliability of an Instrument Measuring Risk of Adverse Outcomes. J Frailty Aging 2015;4:80-89.

25. O'Caoimh R, Gao Y, Svendrovski A, et al. The Risk Instrument for Screening in the Community (RISC): A New Instrument for Predicting Risk of Adverse Outcomes in Community Dwelling Older Adults. BMC Geriatrics 2015;15:92.

26. FitzGerald C, O'Caoimh R, Healy E, et al. Risk Instrument for Screening in the Community (RISC): Predicting Adverse Outcomes in Older Adults. Irish Journal of Medical Science 2014;183 S(7):306-7.

27. Leahy-Warren P, O'Caoimh R, Fitzgerald C, et al. Components of the Risk Instrument for Screening in the Community (RISC) that predict Public Health Nurse perception of risk. J Frailty Aging 2015;4:149-154.

28. O'Caoimh R, FitzGerald C, Cronin U, et al. Which part of a short, global risk assessment, the Risk Instrument for Screening in the Community (RISC), predicts adverse healthcare outcomes? J Aging Res 2015:ID256414.

29. O'Caoimh R, Healy E, O Connell E, Molloy DW. Stratification of the Risk of Adverse Outcomes for Irish, Community Dwelling, Older Adults: Use of a Risk Register. Irish J Med Sci 2012;181 S(7):295.

30. Leahy-Warren P, Weathers E, Lupari M, et al. Risk Instrument for Screening Older People in the Community (RISC): Cross Cultural Perspectives. Int J Res Nurs 2015 in press. DOI: 10.3844/ijrnsp.2015.

31. Sweeney C, Molloy DW, O'Caoimh R, et al. European Innovation Partnership on Active and Healthy Ageing: Ireland and the COLLAGE experience. Irish J Med Sci 2013;182 S(6):278-279.

32. O'Caoimh R, Sweeney C, Hynes H, et al. COLLaboration on AGEingCOLLAGE: Ireland's three star reference site for the European Innovation Partnership on Active and Healthy Ageing (EIP on AHA). Eur Geriatr Med 2015 Volume 6, Issue 5, Pages 505-511. DOI: 10.1159/000433432.

33. Poulshock SW, Deimling GT. Families caring for elders in residence: Issues in the measurement of burden. J Gerontol 1984;39:230-239.

34. Robinson BC. Validation of a caregiver strain index. J Gerontology 1993:38:344-348.

35. Clancy A, Leahy-Warren P, Day MR, Mulcahy H. Primary Health Care: Comparing Public Health Nursing Models in Ireland and Norway. Nursing Res Pract 2013:426107.

36. Rockwood K, Song X, MacKnight C, et al. A global clinical measure of fitness and frailty in elderly people. CMAJ 2005;173:489-495.

37. Friedman SM, Steinwachs DM, Temkin-Greene H, Mukamel DB. Informal Caregivers and the Risk of Nursing Home Admission Among Individuals Enrolled in the Program of All-Inclusive Care for the Elderly. Gerontologist 2006;46:456-463.

38. Kansagara D, Englander H, Salanitro A, et al. Risk prediction models for hospital readmission: a systematic review. JAMA 2011;306:1688-1698.

39. Appelros P, Nydevik I, Viitanen M. Poor outcome after first-ever stroke: Predictors for death, dependency, and recurrent stroke within the first year. Stroke 2003;34:122-126.

40. Forsaa EB, Larsen JP, Wentzel-Larsen T, Alves G. What predicts mortality in Parkinson disease? A prospective population-based long-term study. Neurology 2010; 75:1270-1276.

41. Luppa M, Luck T, Weyerer S, Konig H-H, Brahler E, Riedel-Heller S G Prediction of institutionalization in the elderly: A systematic review. Age Ageing 2010;39:31-38.

42. Landi F, Onder G, Cesari M, et al. Comorbidity and social factors predicted hospitalization in frail elderly patients. J Clin Epidemiol 2004;57:832-836.

43. Holt-Lunstad J, Smith TB, Layton JB. Social Relationships and Mortality Risk: A Meta-analytic Review. PLoS Med 2010;7:e1000316.

44. Lieberman MA, Kramer JH. Factors affecting decisions to institutionalize demented elderly. Gerontologist 1991;31:371-4.

45. Mui AC, Morrow-Howell N. Sources of Emotional Strain among the Oldest Caregivers: Differential Experiences of Siblings and Spouses. Res Aging 1993;15:50-69.

46. O' Caoimh R, Weathers E, O’Donnell R, et al. The Community Assessment of Risk Screening and Treatment Strategies (CARTS) An Integrated Care Pathway to Manage Frailty and Functional Decline in Community Dwelling Older Adults. In: Helfert $\mathrm{M}$ et al. (Eds) ICT4AgeingWell, CCIS 578, Springer International Publishing, Switzerland, pp. 1-16. DOI:10.1007/978-3-319-27695-3_1 